Maksiller sinüs

patolojilerinin konik

ışınlı bilgisayarlı

tomografi ile

değerlendirilmesi

\section{Evaluation of maxillary sinus pathologies using cone beam computed tomography}

Yrd. Doç. Dr. Gülșilay Sayar

İstanbul Medipol Üniversitesi, Diş Hekimliği Fakültesi, Ortodonti A.D., İstanbul

Yrd. Doç. Dr. Kader Aydın

İstanbul Medipol Üniversitesi, Diş Hekimliği Fakültesi, Ağız, Diş ve Çene Radyolojisi A.D., İstanbul

Geliş tarihi: 30 Mayıs 2017

Kabul tarihi: 15 Ağustos 2017

doi: 10.5505/yeditepe.2018.97752

\section{Yazışma adresi:}

Yrd. Doç. Dr. Gülşilay Sayar

İstanbul Medipol Üniversitesi

Diş Hekimliği Fakültesi Ortodonti Anabilim Dalı,

Atatürk Bulvarı No: 2734083 Fatih- İstanbul

Tel: 0212-4534952

Fax: 0212-5210426

gsayar@medipol.edu.tr
ÖZET

Amaç: Bu çalışmanın amacı Konik ışınlı Bilgisayarlı Tomografi (KIBT) görüntüleri üzerinde ikincil olarak teşhis edilen sinüs patolojilerinin görülme sıklığının değerlendirilmesidir.

Gereç ve Yöntem: KIBT görüntülemesi yapılmış 115 hastanın (57 kadın, 58 erkek) retrospektif olarak KIBT görüntüleri incelenmiş, sinüs bulguları değerlendirilirken; bulgular normal, inflamasyon, septum, mukosel, mukozal kalınlaşma ve kompleks problem olarak 6 gruba ayrılmıştır. Normal dağılıma uygun olmayan verilerin karşılaştırımasında Kruskal Wallis testi, kategorik verilerin karşılaştırımasında Pearson Ki-Kare testi kullanılmıştır. Sonuçlar ortanca (minimum-maksimum), frekans ve yüzde olarak sunulmuştur. Anlamlıık düzeyi $p<0,05$ olarak alınmıştır.

Bulgular: Sinüs (antral) septumu 32 sinüste $(\% 13,9)$, mukosel 23 sinüste (\%10), kompleks problemler 18 sinüste $(\% 7,8)$, inflamasyon 11 sinüste $(4,8)$ ve mukozal kalınlaşma 6 sinüste $(\% 2,6)$ saptanmıştır.

Sonuçlar: Çalışmada 90 maksiller sinüste patoloji bulunmuştur ve görülme sıklığı \%39,1'dir. Bu orana kompleks problem içeren 18 sinüs dahildir, sinüs patolojisi gösteren sinüslerin \%20'si birden fazla problem içeren sinüsten oluşmaktadır. Patoloji görülme sıklığı ile cinsiyet arasında istatistiksel olarak anlamlı ilişki kurulmamıştır.

Anahtar kelimeler: Maksiller sinüs, konik ışınlı bilgisayarlı tomografi, sinüs septumu, mukosel.

\section{SUMMARY}

Aim: This study aimed to evaluate type and the prevalance of maxillary sinus pathologies by using cone- beam computed tomography (CBCT).

Materials and Methods: One hundred fifteen (57 female and 58 male subjects) СBCT scans were randomly selected among the archives of orthodontics department. The prevalance of inflammation, mucosal thickening, septum and mucocele of the maxillary sinuses were examined.

Results: The most frequent maxillary sinus pathologies were sinus (antral) septum (32 sinuses, 13.9\%), mucocele (23 sinuses, $10 \%$ ), complex problems (18 sinuses, $7.8 \%$ ), inflammation (11 sinuses, $4.8 \%$ ), and mucosal thickening (6 sinuses, $2.6 \%$ ). Conclusions: The incidence of maxillary sinus findings were found in 90 sinuses (\%39.1). And the 18 sinuses had complex problems. The sinuses that included complex problems had the $\% 20$ percentage in 90 sinuses. And there was no statistically significant relationship between frequency of sinus findings and gender.

Keywords: Maxillary sinus, cone-beam computed tomography, mucocele, sinus septum. 


\section{GíRiş}

Maksiller sinüsler iki boyutlu radyografiler ile değerlendirilebilse de, sinüsleri konik ışınlı bilgisayarlı tomografi (KIBT) ile değerlendirmek sinüs bulgu ve patolojilerinin tanısında daha üstün bir nitelik taşır. ${ }^{1-3}$

Kraniyofasiyal yapıların üç boyutlu görüntülemesinde çok kesitli tomografi tekniği olarak da isimlendirlen Bilgisayarı Tomografi Tekniği (BT) kullanıldığında görüntü boyut problemi veya görüntülerin çakışma problemi olmaksızın görüntüleme yapılabilmektedir ancak KIBT ile BT'ye göre daha az radyasyon dozu ve daha az görüntüleme zamanı ile çalışmak mümkündür.

Diş Hekimliğinde KIBT kullanımı sadece dişlere, periodonsiyum ve kemiğe ait patolojileri saptamaya yardımcı olmakla kalmaz, ayrıca diş hekimliğinde tedavi planı yapmak için de kullanıırı. ${ }^{4,5}$ Ortodontistler, KIBT ile gömülü dişleri kök problemlerini ,süpernümerer dişleri değerlendirebilir ayrıca ortodontik diş hareketi öncesinde mevcut kemik seviyesini de ölçebilir. KIBT kullanımının avantajlarından biri de ortognatik cerrahide tedavi planı planlamasında kullanılmasıdır. ${ }^{4}$ Esas amacı patolojik bulguların saptanması ya da tedavi planı için görüntüleme yapılmış olsa da, KIBT üzerinde ikincil olarak saptanan bulgular olabilmektedir. Maksiller, ethmoidal ve frontal sinüsler, havayolu ile diğer iskeletsel ve yumuşak dokulara ait bulgular da ikincil olarak değerlendirilebilir. ${ }^{5}$

Sinüs patolojilerinin çoğunluğu BT veya KIBT üzerinde tesadüfi olarak saptanmaktadır. Maksiller sinüslere ait bulgular mevcut problemin tedavisi için önemlidir. Kulak-burun-boğaz hastalıkları uzmanı, ortodontistler, diş hekimleri, veya diğer tıp doktorları ilgili problemin çözümünde rol oynarlar. Bu nedenle KIBT'nin dikkatli incelenmesi ve diğer uzmanlar ile konsültasyon önerilmektedir. 6,7

Maksiller sinüs problemleri daha önce yapılan çalışmalarda incelenmiş ve bu patolojilerin klinik bulgu vermeyebildiği rapor edilmiştir. Semptom göstermeyen sinüs problemlerinin \%10,9 ile \%69 arasında bir oran gösterdiği bildirilmiştir. ${ }^{8-10}$

Gracco ve ark. ${ }^{11}$ maksiller sinüslerdeki patolojilerin $\% 56,3$ oranında görüldüğünü belirtmişlerdir. Literatürde, tanı amaçlı kullanılan KIBT ile ilgili çalışmalar mevcuttur ancak KIBT üzerinde ikincil olarak teşhis edilen maksiller sinüs patolojilerinin görülme sıklığını araştıran az sayıda çalışma bulunmaktadır. ${ }^{5,6,12}$ Önceki çalışmalar görüntüleme alanının dar olması ve sinüs patolojilerinin lokalizasyonu ile sınıflaması açısından yeterli bilgi vermemektedir.11,13

Bu retrospektif çalışmanın amacı ortodonti kliniğine başvuran hastalarda başka nedenler ile alınan KIBT görüntüleri üzerinde ikincil olarak bulunan sinüs patolojilerinin görülme sıklığının ve bu bulguların yaş ve cinsiyet ile ilişkisinin değerlendirilmesidir.

\section{GEREÇ VE YÖNTEM}

Bu çalışma genel diş hekimliği ve ortodontik problemler nedeni ile İstanbul Medipol Üniversitesi Diş Hekimliği Fakültesi kliniğine başvuran ve başka nedenler ile KIBT görüntülemesi yapılmış 115 hastanın (57 kadın, 58 erkek) tomografi görüntüleri ile gerçekleştirilmiştir. İlk muayenesi Oral Diagnoz ve Radyoloji bölümünde gerçekleştirilen ve sorasında ortodontik problemleri nedeniyle ortodonti bölümüne yönlendirilen hastalar çalışmamıza dahil edilmiştir.

Çalışmamıza grup içi homojenitenin etkilenmemesi için Angle Sınıf I maloklüzyon gösteren, transversal ve vertikal yön problemi olmayan hastalar dahil edilmiştir.

Kraniyofasiyal problemi olmayan, dental implant veya metal protezleri olmayan bireylerden alınan tomografi görüntüleri çalışmaya dahil edilmiştir.

İstanbul Medipol Üniversitesi Girişimsel Olmayan Klinik Araştırmalar Etik Komitesi çalışmayı 108400987-176 numara ile onaylamıştır. İstatistiksel analizlerin gerçekleştirilmesi için hastalar; 7 - 11, 12-17, 18-22 ve 23-30 olmak üzere 4 yaş grubuna bölünmüştür. Çalışmadaki yaş ve cinsiyet dağılımı Tablo-1'de gösterilmiştir. Tomografiler radyoloji kliniğimizde bulunan tomografi cihazı (i-CAT ${ }^{\circledR}$, Model 17-19, Imaging Sciences International, Hatfield, Pennsylvania, USA) ile alınmıştır. Kliniğimizde görüntüleme ayarları $120 \mathrm{kV}, 5.0 \mathrm{~mA}$ ve 26.9 saniye ve FOV $23 X 17 \mathrm{~cm}$ olarak ayarlanmıştır. Tomografi cihazı her hastadan önce kalibre edilmektedir. Hastalar Frankfort horizontal düzlem yere paralel olacak şekilde ve oturur pozisyonda görüntülenmiştir. Görüntülerin değerlendirmesini tek araştırmacı gerçekleştirmiş ve ölçümleri 2 hafta sonra tekrarlamıştır. Metod hatası Houston formülüne göre hesaplanmış ve hata oranı 0,3 olarak bulunmuştur. ${ }^{14}$

Sinüs bulguları değerlendirilirken; bulgular normal, inflamasyon, septum, mukosel, mukozal kalınlaşma ve kompleks problem olarak 6 gruba ayrıımıştır.

\section{Bulguların değerlendirilmesi;}

Normal: Herhangi bir inflamasyon, septum, mukosel ve mukozal kalınlaşma göstermeyen sinüsler normal olarak kabul edilmiştir. (Şekil-1)

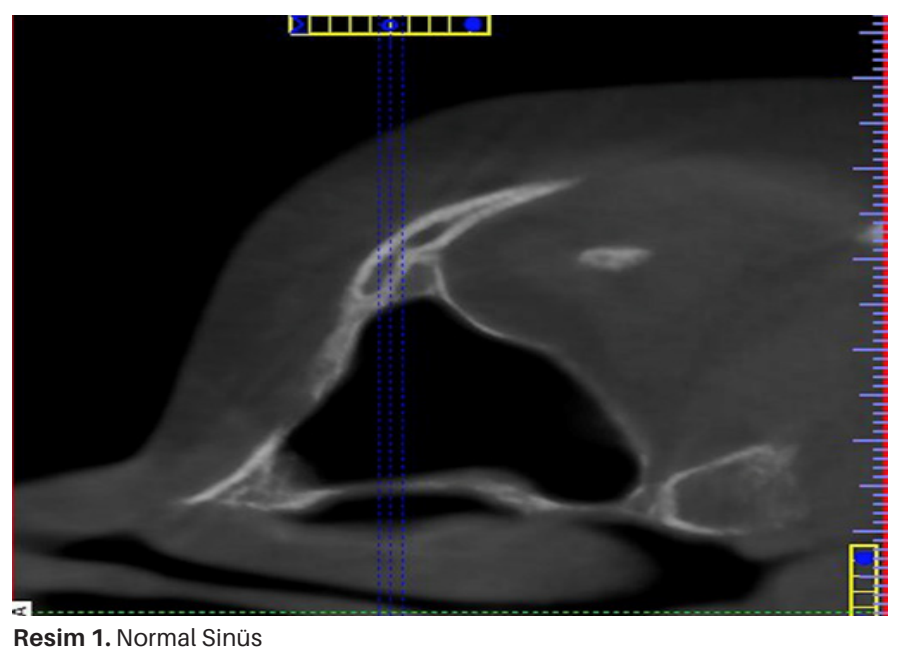


Inflamasyon: Radyolojik olarak sinüste hava hacminin azalması ve radyoopositenin artması ile karakterizedir. (Şekil-2)

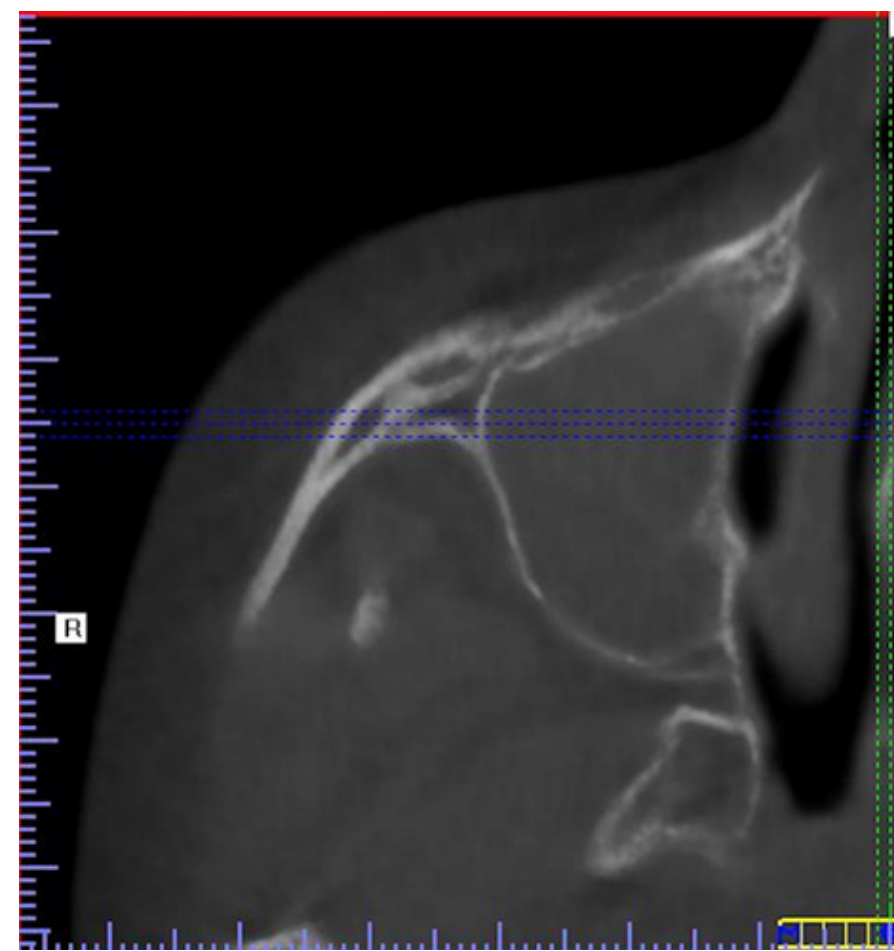

Resim 2. Inflamasyon

Septum: Sinüsü bölen kortikal kemik kemeridir. Sinüsü ikiden fazla parçaya bölebilir. (Şekil-3)

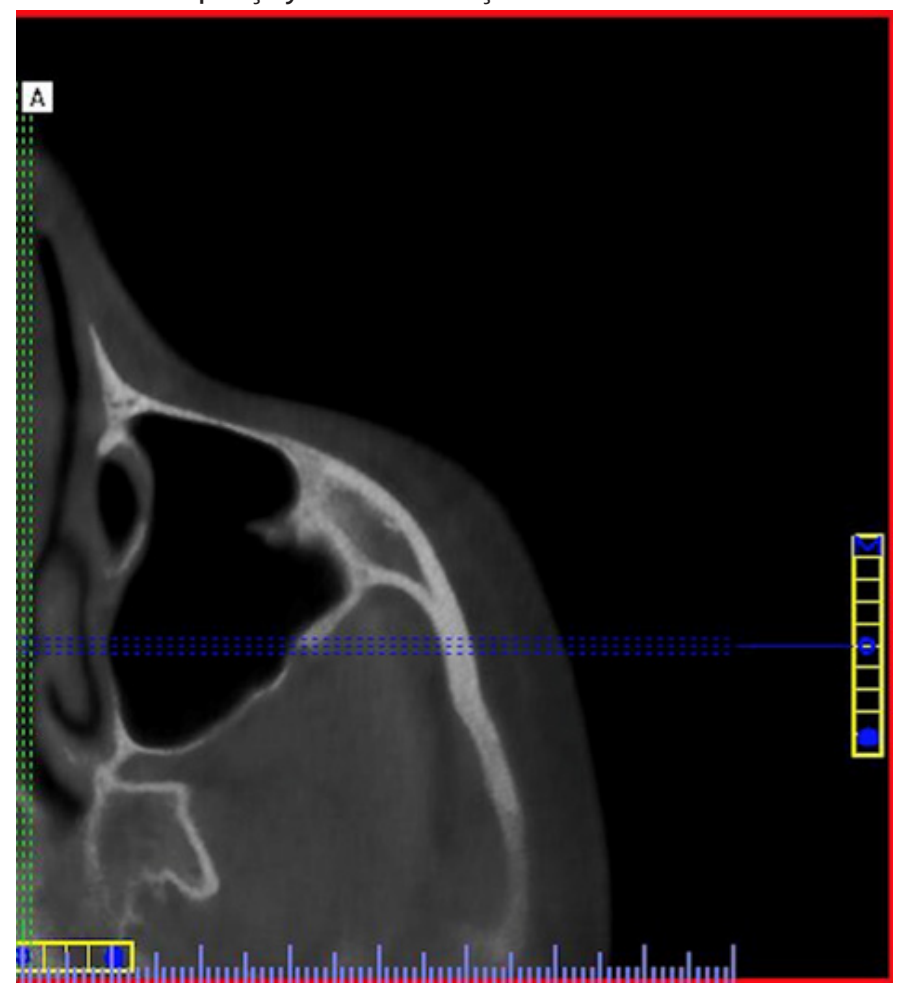

Resim 3. Septum

Mukosel: Kortikal yapıda olmayan, kubbe şeklinde ve homojen radyoopak kütledir. (Şekil-4)

Mukozal kalınlaşma: Sinüs duvarı boyunca paralel seyreden ve sinüsteki havadan daha fazla radyoopak olan durum olarak değerlendirilir. (Şekil-5)
Kompleks problem: Sinüs içinde birden fazla problemin (inflamasyon, septum, mukosel, mukozal kalınlaşma) aynı anda olması olarak değerlendirilmiş̧ir. (Şekil-6)

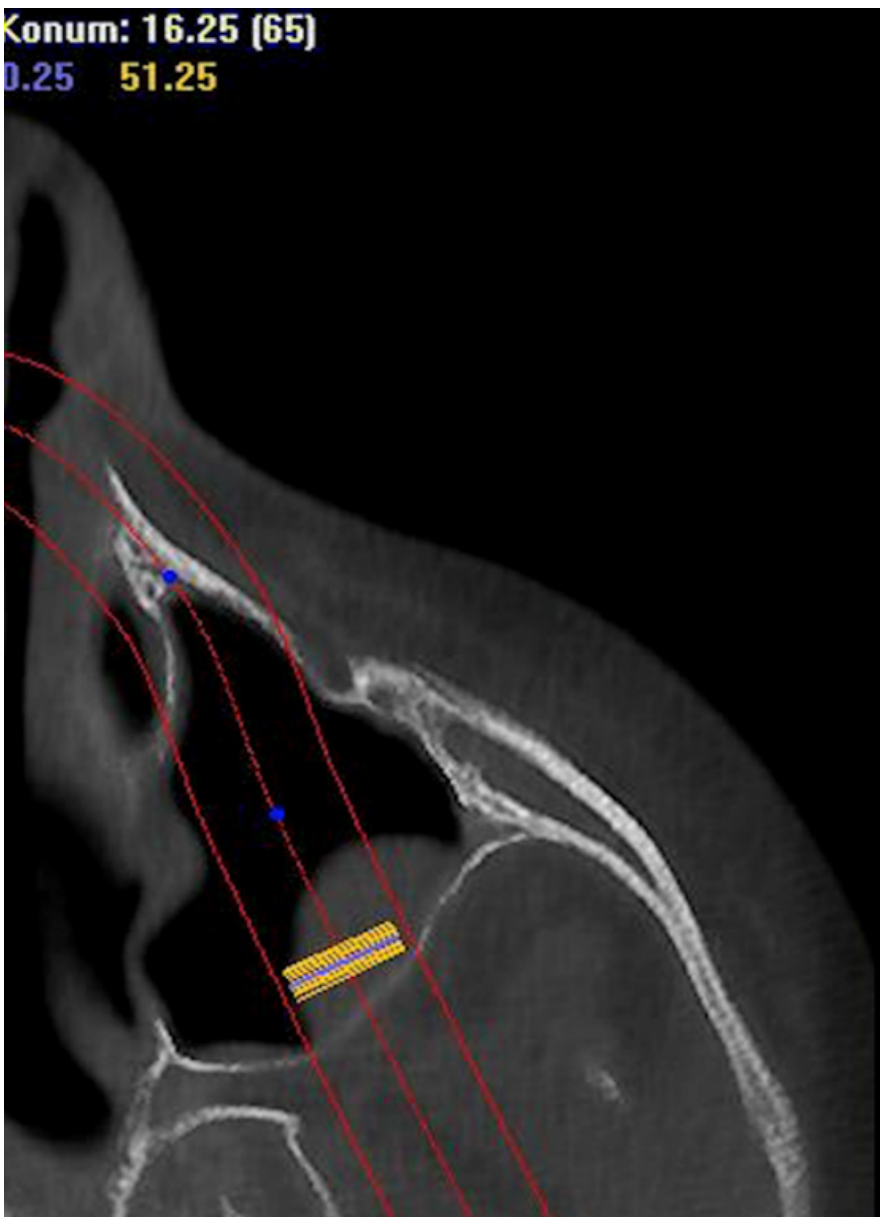

Resim 4. Mukosel

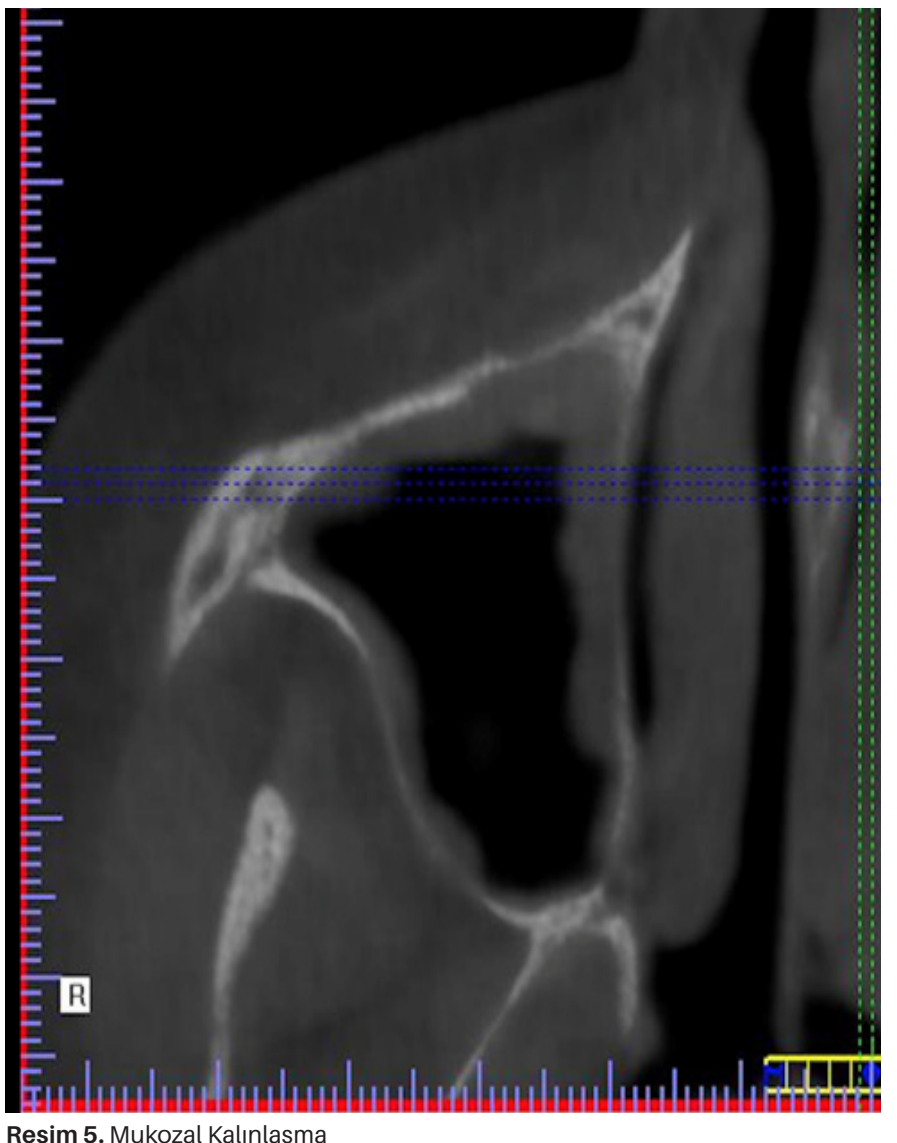




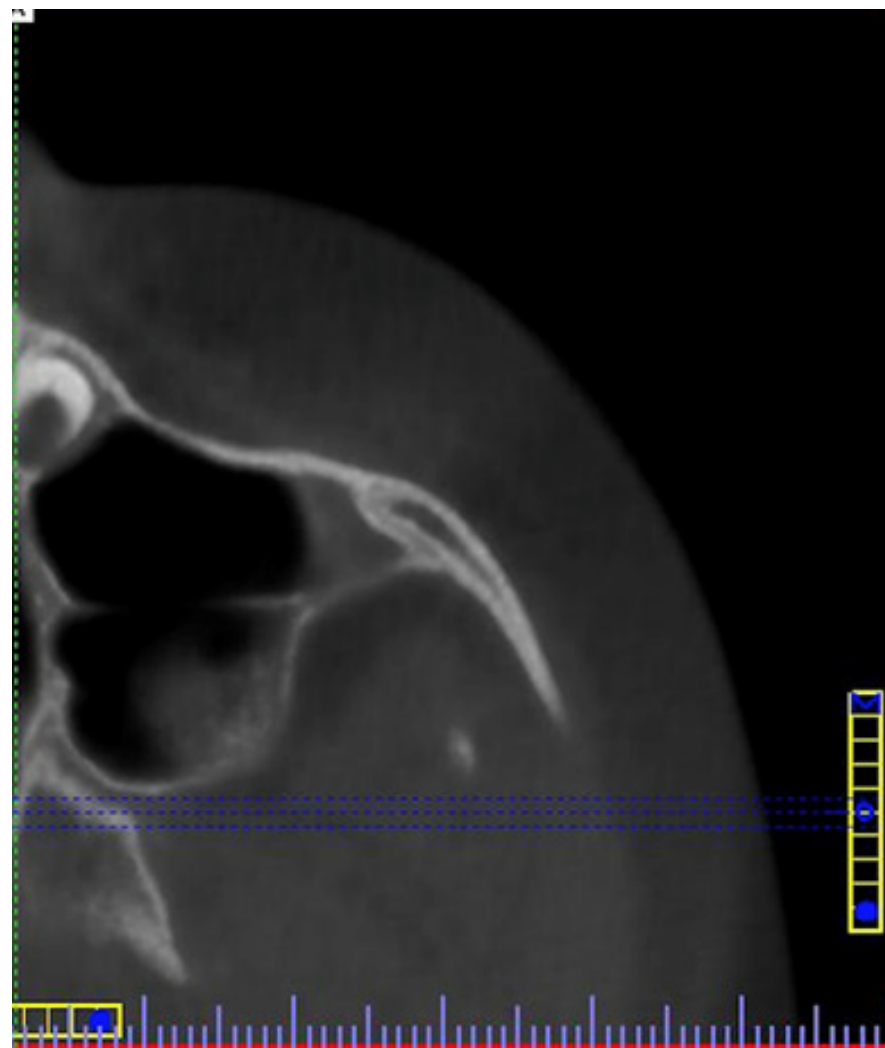

Resim 6. Kompleks Problem

\section{İstatistiksel analiz}

İstatistiksel değerlendirme Statistical Package for Social Science (SPSS for Windows, version 23.0, SPSS Inc., Chicago, USA) ile analiz edildi. Normal dağılıma uygunluk Shapiro Wilk testi ile incelendi. Normal dağılıma uygun olmayan verilerin karşılaştııımasında Kruskal Wallis testi kullanıldı. Kategorik verilerin karşılaştııılmasında ise Pearson Ki-Kare testi kullanıldı. Sonuçlar ortanca (minimum-maksimum), frekans ve yüzde olarak sunuldu. Anlamlılık düzeyi $p<0,05$ olarak alındı.

\section{BULGULAR}

Septum varlığı sinüs patolojileri içinde en sık görüleni olmuştur (\%13,9). En az görüleni mukozal kalınlaşma olmuştur $(\% 2,6,2)$. (Tablo 1)

Tablo 1. Sinüs bulgularının yöne göre dağılımı.

\begin{tabular}{|l|l|l|}
\hline & $\begin{array}{l}\text { Sağ } \\
\text { Frekans (yüzde) }\end{array}$ & $\begin{array}{l}\text { Sol } \\
\text { Frekans (yüzde) }\end{array}$ \\
\hline Normal & $70(60,9)$ & $70(60,9)$ \\
\hline İnflamasyon & $5(4,3)$ & $6(5,2)$ \\
\hline Septum & $15(13)$ & $17(14,8)$ \\
\hline Mukosel & $10(8,7)$ & $13(11,3)$ \\
\hline Mukozal kalınlaşma & $2(1,7)$ & $4(3,5)$ \\
\hline Kompleks Problem & $13(11,3)$ & $5(4,3)$ \\
\hline
\end{tabular}

Sağ ve sol sinüs için normal bulgu sıklığı eşittir. Çalışmadaki 230 sinüste $25^{\prime}$ inde $(\% 21,7)$ iki yönlü problem var iken 40'ında $(\% 34,8)$ tek yönlü problem görülmüştür. (Tablo 2) Normal olanların sayısı ise $50(\% 43,5)$ dir. Çift taraflı ve tek taraflı patolojiler incelendiğinde problem yönünün cinsiyete bağlı olmadığı bulunmuştur. $(p=0,499)$
(Tablo 3) Sinüs patolojilerinin yön dağılımı ile yaş arasında bağımlıık bulunmamıştır. $(p=0,910)$ (Tablo 4).

Tablo 2. Iki yönlü ve tek yönlü bulguların dağılımı.

\begin{tabular}{|l|l|l|}
\hline & Frekans & Yüzde \\
\hline İki yönlü & 25 & 21,7 \\
\hline Tek yönlü & 40 & 34,8 \\
\hline Normal & 50 & 43,5 \\
\hline
\end{tabular}

Tablo 3. Cinsiyete göre problemin yön dağılımı.

\begin{tabular}{|l|l|l|}
\hline & $\begin{array}{l}\text { Kadın } \\
\text { Frekans (yüzde) }\end{array}$ & $\begin{array}{l}\text { Erkek } \\
\text { Frekans (yüzde) }\end{array}$ \\
\hline İki yönlü & $22(38,6)$ & $18(31,0)$ \\
\hline Tek yönlü & $10(17,5)$ & $15(25,9)$ \\
\hline Normal & $25(43,9)$ & $25(43,1)$ \\
\hline$p$ & 0,499 & \\
\hline
\end{tabular}

Ki-Kare testi $*: \mathrm{p}<0.05, * *: \mathrm{p}<0.01, * * *: \mathrm{p}<0.001$

Tablo 4. Yön dağılımı ile yaş iliş̧kisi

\begin{tabular}{|l|l|l|l|}
\hline & $\begin{array}{l}\text { İki yönlü } \\
\text { Frekans (yüzde) }\end{array}$ & $\begin{array}{l}\text { Tek yönlü } \\
\text { Frekans (yüzde) }\end{array}$ & $\begin{array}{l}\text { Normal } \\
\text { Frekans (yüzde) }\end{array}$ \\
\hline $7-11$ yaş & $21(38,2)$ & $11(20,0)$ & $23(41,89$ \\
\hline $12-17$ yaş & $16(34,89$ & $10(21,7)$ & $20(43,5)$ \\
\hline $18-22$ yaş & $2(22,2)$ & $2(22,2)$ & $5(55,6)$ \\
\hline $23-30$ yaş & $1(20,0)$ & $2(40,0)$ & $2(40,0)$ \\
\hline$p$ & 0,910 & & \\
\hline
\end{tabular}

Ki-Kare testi $*: p<0.05, * *: p<0.01, * * *: p<0.001$

\section{TARTIŞMA}

Bu çalışma diğer dişsel sebepler nedeniyle KIBT görüntüsü alınmış 115 hastanın tomografileri üzerinde sinüs patolojilerinin belirlenmesi amacı ile yapılmıştır. Çalışmaya dahil edilen 115 hastada tek taraflı patolojilerin çift tarafı patolojilerden daha sık olduğu görülmüştür. Daha önce yapılan çalışmalarda sinüs patolojilerinin görülme sıklığı farklı oranlarda rapor edilmiştir. Bunun nedeninin çalışmalardaki bireylere ait yaş, cinsiyet ve çalışmalarda kullanılan KIBT görüntüleme ayarlarındaki farklılıktan kaynaklandığını düşünmekteyiz. 5,12,13,15,16

Maksiller sinüslere ait patolojiler başka semptomlar vererek burun pasajını tıkamakta ve solunum fonksiyonunu etkilemektedir. Bozulmuş burun solunumu maloklüzyon gelişiminde etyolojik faktörler arasında yer alabilmektedir. ${ }^{17-20}$ Solunumun bozulması ile büyümekte olan bireylerde kraniyofasiyal gelişim de bozulabilmektedir. Bu nedenle ortodontik amaçlı yapılan muayeneye ek olarak alınan radyografiler bu açıdan değerlendirilmelidir. Çalışmamızda ortodonti kliniğine başvuran hastalarda ikincil olarak sinüs patolojilerinin değerlendirilmesi, görülebilecek patoloji sıklığını ve çeşidini belirlemek amacı ile gerçekleştirilmiştir. Bu çalışmanın bir başka faydası, tesbit 
edilen probleme göre ilgili uzmanlık alanına yönlendirme yetkinliğinin kazanılmasıdır.

Sinüslerde patoloji görülme sıklığı çalışmamızda $\% 39,1$ oranında bulunmuştur. Cho ve Jung ${ }^{15}$ çalışmalarında bu oranı bizim çalışmamıza yakın olarak $\% 37,7$ olarak bildirmişerdir. Pazera ve ark. ${ }^{13}$ sinüs patolojilerinin görülme sıklığını \%46,8, Ritter ve ark. ${ }^{12} \% 56,3$, Raghav ve ark. ${ }^{5} \% 59,7$, Rege ve ark. ${ }^{16} \% 68,2$ ayrıca olarak rapor etmişlerdir.

Çalışmamızda en sık görülen sinüs patolojisi septum olarak tesbit edilmiştir bunu sırayla mukosel, kompleks problemler, inflamasyon ve mukozal kalınlaşma izlemiştir. Daha önce yapılan çalışmalarda çoğunlukla mukozal kalınlaşma en sık görülen patoloji olarak bildirilmiştir., ${ }^{5,12,16}$ Kim ve ark. ${ }^{21}$ çalışmalarında sinüs septumunun görülme sıklığını $\% 26,5$ olarak bulmuştur. Özeç ve ark. ${ }^{22}$ sinüs septumunun görülme sıklığını \%13,7 olarak bildirmişlerdir ve bu sonuç çalışmamızınkine yakındır. Farklı radyografi teknikleri ile yapılan görüntülemelerde sinüs septum sıklığı \%16-\%58 arasında rapor edilmiştir. ${ }^{23-25}$ Damlar ve ark. ${ }^{26}$ dişlerin varlığı veya kaybedilmesinin maksiller sinüs septa oluşumu üzerinde etkili olduğunu belirtmişlerdir.

Gracco ve ark. ${ }^{11}$ mukozal kalınlaşma ve psödokist sıklığını değerlendirdikleri çalışmalarında psödokist görülme sıklığını $(\% 25,1)$, mukozal kalınlaşmadan fazla bulmuşlardır. Rege ${ }^{16}$ çalışmasında mukozal kalınlaşmayı $\% 66,0$ oranında bulmuş ve en sık görülen sinüs patolojisi olduğunu belirtmiştir aynı şekilde Raghav ve ark. ${ }^{5}$ en sık görülen bulgu olarak saptamışlar ve oranı \%35,1 olarak bildirmişlerdir. Çalışmamızda yaş gruplarına göre tek ve çift taraflı patolojiler değerlendirildiğinde, küçük yaştaki bireylerde (7-11 yaş) çift taraflı patolojiler, daha büyük yaş grubunda (2330 yaş) tek taraflı patolojiler saptanmıştır. Çalışmamızın sonuçları, Raghav ve ark. ${ }^{5}$ tarafından yapılan ve yaşamın 3 . on yıllık döneminde (20-30 yaşlar) daha çok sinüs patolojisinin görüldüğünü belirten çalışma ile uyumludur. Ritter ve ark. ${ }^{12} 60$ yaş üzerindeki grubun en yüksek sinüs patolojisini gösterdiğini bildirmişlerdir ancak çalışmamızda 30 yaş üzerinde birey mevcut değildir.

Bu çalışmada kadın ve erkek grubu karşılaştıııdığında çift taraflı sinüs patolojilerinin kadınlarda, tek taraflı patolojilerin ise erkeklerde daha fazla görüldüğü tespit edilmiştir. Ancak toplamda görülen sinüs patolojilerinin cinsiyet farklıığı ile ilişkili olmadığı saptanmıştı bu bulgu daha önce yapılan bir başka çalışma ile uyumludur. ${ }^{5}$

Ortodonti kliniklerine başvuran ve KIBT alınmış hastalarda, detaylı tomografi incelemesi yapıldığında ikincil önemli bölgelerdeki patolojileri saptamak hastayı tespit edilen problemin tedavisi için ilgili uzman doktora yönlendirmek adına önemlidir. Ayrıca solunum fonksiyonunu bozacak patolojilerin tesbiti ve tedavilerinin sağlanması ile, büyümekte olan bireylerin kraniyofasiyal yapılarında oluşabilecek olumsuz etkilerin önüne geçilebilmesi mümkündür.
Çalışmamızın zayıf yanı maloklüzyon gruplarına göre sinüs patolojilerini değerlendirmemiş olmamızdır.

\section{SONUC}

Sinüs patolojisi görülme sıklığı tüm sinüslerin yarısından daha az oranda görülmüş ve en sık görülen problem septum olmuştur. Tek taraflı problemler daha fazla görülmekle birlikte sinüs patolojisi görülmesinin cinsiyet ile ilişkili olmadığu bulunmuştur. Sadece 18-22 yaş grubunda ikincil sinüs patolojileri görülme sıklığı \%50 oranındadır.

\section{KAYNAKLAR}

1. Horner $K$, Islam M, Flygare L, Tsiklakis $K$, Whaites E. Basic principles for use of dental cone beam computed tomography: consensus guidelines of the European Academy of Dental and Maxillofacial Radiology. Dentomaxillofac Radiol 2009; 38: 187-195.

2. Anzai Y, Yueh B. Imaging evaluation of sinusitis: Diagnostic performance and impact on health outcome. Neuroimaging Clin N Am 2003; 13: 251-263. xi.

3. Mafee MF, Tran BH, Chapa AR. Imaging of rhinosinusitis and its complications: Plain film, CT, and MRI. Clin Rev Allergy Immunol 2006; 30: 165-186.

4. Guttenberg SA. Oral and maxillofacial pathology in three dimensions. Dent Clin North Am 2008; 52: 843-873, viii.

5. Mamta Raghav, Freny R. Karjodkar, Subodh Sontakke, Kaustubh Sansare. Prevalence of incidental maxillary sinus pathologies in dental patients on cone-beam computed tomographic images. Contemp Clin Dent 2014; 5: 361-365.

6. Cha JY, Mah J, Sinclair P. Incidental findings in the maxillofacial area with 3-dimensional cone-beam imaging. Am J Orthod Dentofacial Orthop 2007; 132: 7-14.

7. Rogers SA, Drage N, Durning P. Incidental findings arising with cone beam computed tomography imaging of the orthodontic patient. Angle Orthod 2011; 81: 350-355. 8. Havas TE, Motbey JA, Gullane PJ. Prevalence of incidental abnormalities on computed tomographic scans of the paranasal sinuses. Arch Otolaryngol Head Neck Surg 1988;114: 856-859.

9. Nam EC, Lee BJ. Prevalence of sinus abnormality observed in the cranial computed tomograms taken to evaluate head injury patients. Korean J Otolaryngol 1998; 41: 488-492.

10. Min YG, Choo MJ, Rhee CS, Jin HR, Shin JS, Cho YS. $\mathrm{CT}$ analysis of the paranasal sinuses in symptomatic and sysmptomatic groups. Korean J Otolaryngol 1993; 35: 916-925.

11. Gracco A, Parenti SI, loele C, Bonetti GA, Stellini E. Prevalence of incidental maxillary sinus findings in Italian orthodontic patients: a retrospective cone-beam computed tomography study Korean J Orthod 2012; 42: 329-334. 
12. Ritter L, Lutz J, Neugebauer J, Scheer M, Dreiseidler T, Zinser MJ, . Prevalence of pathologic ndings in the maxillary sinus in cone-beam computerized tomography. Oral Surg Oral Med Oral Pathol Oral Radiol Endod 2011; 111: 634-40.

13. Pazera P, Bornstein MM, Pazera A, Sendi P, Katsaros C. Incidental maxillary sinus findings in orthodontic patients: a radiographic analysis using cone-beam computed tomography (CBCT). Orthod Craniofac Res 2011; 14: 17-24. 14. Houston WJB. The analysis of errors in orthodontic measurements. Am J Orthod 1983; 83: 382-390.

15. Cho BH, Jung YH. Prevalence of incidental paranasal sinus opacification in an adult dental population. Korean J Oral Maxillofac Radiol 2009; 39: 191-194.

16. Rege IC, Sousa TO, Leles CR, Mendonça EF. Occurrence of maxillary sinus abnormalities detected by cone beam CT in asymptomatic patients. BMC Oral Health 2012; 12: 30.

17. Aksakallı $S$, Yılmaz B, Birlik $M$, Dadaşlı $F$, Bölükbaşı $E$. Between Maxillary Sinus Findings and Skeletal Malocclusion? Turk J Orthod 2015; 28: 44-47.

18. Jani AL, Hamilos DL. Current thinking on the relationship between rhinosinusitis and asthma. J Asthma 2005; 42: 1-7.

19. Maksiller sinüs mukoseli. Bal M, Yıldırım G, Kuzdere $M$, Hatipoğlu A, Uyar Y. Okmeydanı Tıp Dergisi 2011; 27: 114117.

20. Agren $K$, Nordlander $B$, Linder-Aronsson $S$, Zettergren-Wijk L, Svan- borg E. Children with nocturnal upper airway obstruction: postop- erative orthodontic and respiratory improvement. Acta Otolaryn- gol 1998; 118: 581-7. 21. Kim MJ, Jung UW, Kim CS, Kim KD, Choi SH, Kim CK, Cho KS. Maxillary Sinus Septa: Prevalence, Height, Location, and Morphology. A Reformatted Computed Tomography Scan Analysis J Periodontol 2006; 77: 903-908.

22. Özeç I, Kiliç E, Müderris S. Maksiller sinüs septa: bilgisayarli tomografi ve panoramik radyografi ile değerlendirme, Cumhuriyet Dental Journal; 11: 82-86.

23. Van den Bergh JP, ten Bruggenkate CM, Disch FJ, Tuinzing DB. Anatomical aspects of sinus floor elevations. Clin Oral Implants Res 2000; 11: 256-265.

24. Ulm CW, Solar P, Krennmair G, Matejka M, Watzek G. Incidence and suggested surgical management of septa in sinus lift procedures. Int Oral Maxillofac Implants 1995; 10: 462-465.

25. Krennmair G, Ulm CW, Lugmayr H, Solar P. The incidence, location, and height of maxillary sinus septa in the edentulous and dentate maxilla. J Oral Maxillofac Surg 1999; 57: 667-671.

26. Damlar I, Evlice B, Kurt Ş. Dental volumetric tomographical evaluation of location and prevalence of maxillary sinus septa. Cukurova Medical Journal 2013; 38: 467-474. 